\title{
PERANCANGAN TATA KELOLA TEKNOLOGI INFORMASI MENGGUNAKAN FRAMEWORK COBIT PADA PT. BIRO KLASIFIKASI INDONESIA MAKASSAR
}

\author{
Febri Hidayat Saputra \\ Teknik Informatika STMIK AKBA \\ Email: febri@akba.ac.id
}

\begin{abstract}
ABSTRAK
PT. Biro Klasifikasi Indonesia ( Persero ) Cabang Makassar merupakan perusahaan BUMN ( Badan Usaha Milik Negara ). Sebagai perusahan yang besar tentunya menerapkan TI sebagai salah satu cara untuk mencapai tujuan bisnisnya. Namun masih terdapat kendala dalam pemanfaatan TI, sehingga tujuan dari bisnis perusahaan belum tercapai.Tujuan yang ingin dicapai dalam penelitian ini adalah untuk mengetahui kondisi tata kelola teknologi informasi yang berjalan selama ini di PT. BKI (Persero ) Cabang Makassar, membantu menemukan kebutuhan manajemen, merancang penerapan tata kelola TI yang dapat memecahkan, mencegah permasalahan yang mengacu pada praktek terbaik dari COBIT 4.1.Metode penelitian yang digunakan yaitu mengetahui gambaran umum perusahaan, studi pustaka, pengumpulan data, menilai kematangan/maturity proses, menentukan tingkat kematangan/maturity, memberikan rekomendasi strategi perbaikan, dan menarik kesimpulan.Dari hasil penelitian proses TI terpilih sebanyak sepuluh proses secara mayoritas tingkat kematangan/maturity tata kelola TI PT. BKI Cabang Makassar saat ini berada pada level tiga atau Define. Target tingkat kematangan/maturity TI yang ingin dicapai pada level empat atau Manage and Measureable.Untuk mencapai tingkat kemtangan/maturity yang diinginkan, dapat direkomendasikan tiga hal yaitu memiliki ukuran kuantitatif yang dijadikan sasaran kinerja proses teknologi informasi, mempunyai fasilitas memonitor dan mengukur prosedur yang sudah berjalan, diperbaiki terus menerus dan dibandingkan dengan praktek terbaik tata kelola TI.
\end{abstract}

Kata Kunci : COBIT, TI, Tata Kelola.

\begin{abstract}
PT. The Indonesian Classification Bureau (Persero) Makassar Branch is a BUMN (State-Owned Enterprise) company. As a large company determine IT as one way to achieve business goals. However, it still needs improvement in the implementation of IT, so that the goals of the company have not been achieved. The aim to be achieved in this research is to study the conditions of information governance that are carried out so far at PT. BKI (Persero) Makassar Branch, helps find management needs, discusses IT governance arrangements that can overcome, overcome debates that discuss the best practices of COBIT 4.1. The research method used is to find general company guidelines, study literature, connect data, ensure maturity / due process, determine the level of maturity / maturity, provide recommendations for improvement, and draw conclusions. Makassar Branch BKI is currently at level three or Decide. Target the level of IT maturity / maturity to be achieved at level four or Manage and
\end{abstract}


Measured. To achieve the desired level of maturity / maturity, the following three things can be accessed with the necessary quantitative measures. running, improved continuously and compared to IT best practices.

\section{Keywords : COBIT, IT, framework.}

\section{PENDAHULUAN}

Saat ini, teknologi informasi tidak hanya digunakan sebagai faktor pendukung dalam perusahaan, tetapi juga sebagai bagian dari strategi bisnis perusahaan. Agar teknologi informasi dapat digunakan secara optimal, diperlukan suatu tata kelola yang biasa disebut tata kelola teknologi informasi.Tata kelola teknologi informasi adalah bagian dari tata kelola perusahaan yang menitik beratkan pada sistem dan teknologi informasi serta manajemen kinerja dan resikonya.

Kemajuan dari teknologi informasi dan juga pemanfaatannya terus meningkat dari waktu ke waktu, kecepatan dan keakuratan informasi akan menjadi suatu tuntutan dalam menjalankan roda perokonomian baik oleh pelaku bisnisnya sendiri maupun oleh masyarakat dan juga pemerintah. Penerapan teknologi informasi pada proses bisnis suatu perusahaan dipandang sebagai salah satu solusi yang kemudian akan dapat meningkatkan daya saing perusahaan.

Tata kelola teknologi informasi mempunyai banyak sekali standar tools yang dapat digunakan. Salah satunya adalah COBIT ( Control Objective For Information and Related Technology ). COBIT framework menyediakan ukuran, indikator, proses dan kumpulan praktik terbaik untuk membantu perusahaan optimal dari pengelola teknologi informasi dan mengembangkan pengendalian terhadap manajemen tata kelola teknologi informasi yang layak untuk suatu perusahaan atau organisasi.

Secara umum kerangka kerja tata kelola serta pengendalian yang dibutuhkan untuk mencapainya sudah disediakan oleh COBIT. Dimana didalamnya terdapat panduan bagaimana organisasi harus mengendalikan pengelolaan tekno ${ }^{1 \sim \cdots}$ informasi dalam pencapaian governal Akan tetapi COBIT hanya memberikan sebuah control dan tidak memberikan panduan implementasi operasionalnya.

Tata kelola teknologi informasi diharapkan mendapat dukungan dari para pemangku kepentingan, agar pengembangan dari implementasi sistem teknologi informasi sesuai anggaran dan tepat waktu dengan kualitas yang tinggi. Akan tetapi tata kelola teknologi informasi dapat memiliki beberapa masalah yaitu teknologi informasi hanya menjadi perhatian dari tim tehnik dan tidak mendapat perhatian dari manajemen puncak, sehingga dapat menimbulkan kerugian keuangan, rusaknya reputasi proyek karena pendanaannya melebihi rencana semula, waktu penyelesaiannya terlambat, dan spefikasi dibawah rencana awal, penurunan efektifitas karena buruknya kualitas output sistem, tingginya keluhan pengguna mengenai kualitas sistem, dan rendahnya tingkat ketersediaan informasi.

PT. Biro Klasifikasi Indonesia (Persero) Cabang Makassar merupakan salah satu perusahaan BUMN ( Badan 
Usaha Milik Negara ). Sebagai perusahan yang besar PT. Biro Klasifikasi Indonesia Cabang Makassar sudah tentu menerapkan teknologi informasi sebagai salah satu cara untuk mencapai tujuan bisnis dari perusahaan tersebut. Namun masih terdapat kendala-kendala dalam pemanfaatan teknologi informasi tersebut sehingga tujuan dari bisnis perusahaan belum mencapai harapan.

\section{LANDASAN TEORI COBIT FRAMEWORK}

Profile Cobit

Control objective for Information and Related Technology ( COBIT ) adalah sekumpulan dokumentasi best practice untuk IT Governance yang dapat membantu auditor atau pengguna (user) dan manajemen, untuk menjembatani gap antara resiko bisnis, kebutuhan control dan masalah-masalah IT ( Sasongko, 2009 ).

Control objective for Information and Related Technology ( COBIT ) mendukung tata kelola teknologi informasi dengan menyediakan kerangka kerja untuk mengatur keselarasan teknologi informasi dengan bisnis, selain itu kerangka kerja juga memastikan bahwa teknologi informasi memungkinkan bisnis, memaksimalkan keuntungan, resiko teknologi informasi dikelola secara tepat, dan sumberdaya teknologi digunakan secara bertanggung jawab ( Tanuwijaya dan Sarno 2010 ).

COBIT merupakan standar yang dinilai paling lengkap dan menyeluruh sebagai framework teknologi informasi karna dikembangkan secara berkelanjutan oleh lembaga swadaya professional yang tersebar hampir diseluruh negara. Dimana di setiap Negara dibangun chapter yang dapat mengelola para profesional tersebut.
Control objective for Information and Related Technologi ( COBIT ) memberikan sebuah kebijakan yang cukup jelas dan pratik yang baik dalam tata kelola teknologi informasi dengan membantu manajemen senior dalam memahami dan mengelola resiko yang terkait dengan tata kelola teknologi informasi dan panduan tujuan pengendalian terinci / detailed control objective bagi pihak manajemen, pemilik proses bisnis, pengguna.

Untuk dapat memahami kerangka kerja COBIT, perlu diketahui bahwa COBIT mempunyai karakteristik utama. Adapun karakteristik utama dari kerangka kerja COBIT adalah fokus pada bisnis, orientasi pada proses, berbasis control dan dikendalikan oleh pengukuran.

\section{METODE}

\subsection{Metode Dan Alur Pembahasan}

Pada bagian ini akan dijelaskan mengenai metodelogi yang digunakan oleh penulis dalam melakukan penelitian ini. Metodelogi merupakan cara dan urutan pengerjaan yang nantinya akan digunakan dalam penelitian ini. Selain itu metodelogi juga menentukan output yang diharapkan dari setiap masukan yang ada. Tujuan dari metodelogi penelitian ini agar proses yang ada menjadi lebih teratur dan sistematis. Selain tiu juga diharapkan akan mudah memantau perkembangan dan tingkat keberhasilan dari tesis yang dibuat.

Penelitian ini merupakan penelitian yang melakukan evaluasi untuk melihat sejauh mana tingkat kematangan/maturity level sistem informasi di PT. Biro Klasifikasi Indonesia Cabang Makassar dan memberikan analisis perbaikan untuk meningkatkan tata kelola teknologi informasi sesuai dengan proses bisnis yang 
terjadi di PT. Biro Klasifikasi Indonesia Cabang Makassar. Secara garis besar, penelitian ini akan mendeskripsikan bagaimana penerapan tata kelola teknologi informasi yang terjadi di PT. Biro Klasifikasi Indonesia Cabang Makassar. Penelitian ini akan menggunakan studi kasus, karena dengan studi kasus penulis dapat mendapatkan suatu pemahaman tentang suatu kejadian.

Alur penelitian yang akan dilaksanakan adalah :

1. Mengetahui gambaran umum PT. Biro Klasifikasi Indonesia Cabang Makassar tentang latar belakang dan profile perusahaan tersebut, dan bagaimana proses bisnis yang berjalan selama ini di PT. Biro Klasifikasi Indonesia Cabang Makassar.

2. Melakukan studi pustaka atau meninjau kepustakaan sebagai langkah untuk memahami proses penelitian tentang evaluasi tata kelola TI, dengan mempelajari literatur-literatur baik cetak maupun elektronik dan juga menelaah dokumen-dokumen yang terkait dengan penelitian yang ada di PT. Biro Klasifikasi Indonesia Cabang Makassar.

3. Melakukan identifikasi masalah terkait dengan penelitian di PT. Biro Klasifikasi Indonesia Cabang Makassar, mempermasalahkan suatu variable dan hubungan antara variable dan fenomena yang ada di perusahaan tersebut, dan menentukan masalah apa yang akan dibahas dalam penelitian di PT. Biro Klasifikasi Indonesia Cabang Makassar.

4. Mengumpulkan data terkait dengan penelitian perancangan tata kelola TI, melalui proses wawancara, observasi, dan penyebaran kuesioner kepada responden yang terkait dan relevan dengan penelitian ini.

5. Menilai kematangan TI terpilih. Penilaian kematangan proses TI bertujuan untuk menentukan tingkat kematangan/maturity level dari setiap proses yang dibutuhkan. Penilaian tersebut dilakukan dengan mengidentifikasi keberadaan dan kondisi setiap proses TI terpilih pada pengelolaan TI yang sudah ada di PT. Biro Klasifikasi Indonesia Cabang Makassar. Fakta yang ditemukan kemudian dipetakan dalam COBIT 4.1Maturity Tool. Hasil yang diperoleh menunjukan tingkat kematangan/maturity setiap proses TI pada kondisi existing/ saat ini (as is ).

6. Menentukan target tingkat kematangan/maturity proses TI terpilih. Target kematangan/maturity proses TI adalah kondisi ideal tingkat kematangan dari setiap proses TI yang diinginkan ( to be ) yang akan menjadi acuan dalam evaluasi tata kelola TI yang akan diimplementasikan. Target kematangan/maturity untuk setiap proses TI akan ditentukan dengan melihat tingginya ekspektasi pihak manajemen PT. Biro Klasifikasi Indonesia Cabang Makassar terhadap kebutuhan poroses TI yang didasarkan kepada tingkat kematangan/maturity pada atribut Awareness and Communication (AC), Policies, Standard, and Procedure ( PSP ), Tool and Automation ( TA ), Skill and expertise ( SE ), Responsibility and Accountability ( RA), dan Goal Setting and Measurement (GSM) pada masing-masing proses TI terpilih.

7. Memberikan rekomendasi berupa strategi perbaikan terkait dengan kesenjangan/gap guna menutup kesenjangan/gap atribut kematangan/maturity yang menjadi prioritas untuk didetailkan, sehingga evaluasi tata kelola TI di PT. Biro Klasifikasi Indonesia Cabang Makassar dapat berjalan dengan lebih efektif dan efisien.

8. Menarik Kesimpulan dan memberikan saran. 


\subsection{Tahapan Analisis}

Setelah data yang dikumpulkan, maka kemudian data tersebut akan dianalisis dengan tahapan seperti pada gambar 1 . berikut ini :

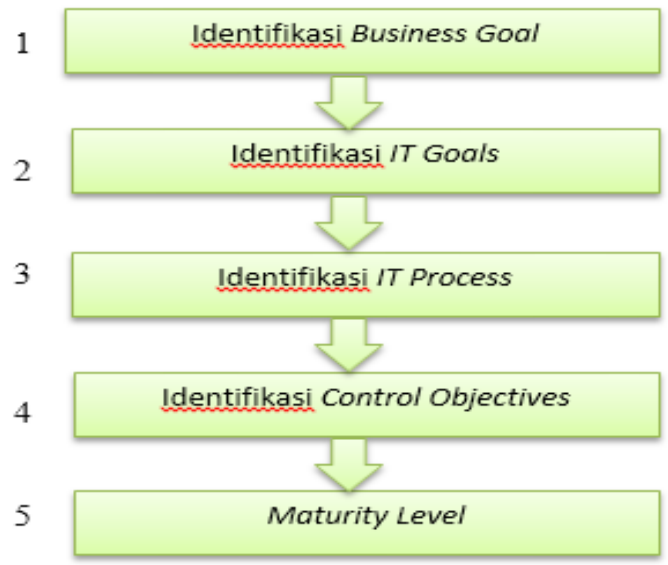

Gambar 1. Tahap Analisis

\section{HASIL DAN PEMBAHASAN}

\subsection{Identifikasi Tujuan Bisnis/Business Goals}

Pada tahap ini akan didefenisikan business goal yang berlaku di COBIT 4.1 yang diselaraskan dengan tujuan bisnis dan sasaran dari perusahaan. Hal yang pertama kali dilakukan pada tahap ini adalah mengidentifikasi tujuan bisnis dan sasaran PT. Biro Klasifikasi Indonesia Cabang Makassar, yaitu :

a. Terciptanya kesempatan usaha dan lapangan kerja yang lebih luas bagi usaha kecil dan koperasi. b. Terselenggaranya sistem manajemen yang lebih rasional dan efesien.

c. Menyampaikan aspek-aspek keselamatan untuk pelayaran.

d. Memberikan penegetahuan kepemilik kapal tentang kelayakan kondisi kapal dari segi konstruksi, instalasi mesin dan statutoria yang berhubungan dengan aspek keselamatan dilaut.

e. Peningkatan kemampuan baik pemodalan, personil, administrasi, keuangan maupun kemandirian wirausaha.

f. Klasifikasi kelas dunia yang kompetitif, aman, andal, dan efisien.

g. Nama BKI dijadikan merek dagang / trade mark yang bermakna produk unggulan.

h. Membangun budaya perusahaan yang sehat tercipta saling menghargai dan terbentuk integritas pribadi dan profesionalisme.

i. Pengendalian dan dukungan pengambilan keputusan dalam hal pelaporan yang actual, akurat, andal dan multi dimensi, dan real-time online monitoring system.

Setelah dirumuskan tujuan dan sasaran bisnis PT.Biro Klasifikasi Indonesia Cabang Makassar selanjutnya akan dilakukan pemetaan dari tujuan dan sasaran bisnis tersebut dengan business goals yang ada di COBIT 4.1, berikut :

Tabel 1. Hasil Pemetaan Tujuan Bisnis PT. Biro Klasifikasi Indonesia Cabang Makassar Dengan COBIT 4.1

\begin{tabular}{|c|c|l|c|}
\hline NO & \multicolumn{1}{|c|}{$\begin{array}{c}\text { Business goals COBIT } \\
\mathbf{4 . 1}\end{array}$} & $\begin{array}{l}\text { Tujuan dan sasaran PT. Biro } \\
\text { Klasifikasi Indonesia Cabang } \\
\text { Makassar }\end{array}$ & $\begin{array}{c}\text { Prespektif } \\
\text { business golas } \\
\text { COBIT 4.1 }\end{array}$ \\
\hline 1. & $\begin{array}{l}\text { Provide a good return on } \\
\text { investment of IT-enabled } \\
\text { business investment. }\end{array}$ & $\begin{array}{l}\text { Peningkatan kemampuan baik } \\
\text { pemodalan, personil, administrasi, } \\
\text { keuangan maupun kemandirian } \\
\text { wirausaha }\end{array}$ & $\begin{array}{c}\text { Financial } \\
\text { Perspective }\end{array}$ \\
\hline
\end{tabular}




\begin{tabular}{|c|c|c|c|}
\hline 2. & $\begin{array}{l}\text { Improve costumer } \\
\text { orientation and service. }\end{array}$ & $\begin{array}{l}\text { Memberikan pengetahuan ke } \\
\text { pemilik kapal tentang } \\
\text { kelayakan kondisi kapal dari } \\
\text { segi konstruksi, instalasi mesin } \\
\text { dan statutoria yang } \\
\text { berhubungan dengan aspek } \\
\text { keselamatan dilaut. } \\
\text { - Klasifikasi kelas dunia yang } \\
\text { kompetitif, aman, andal, dan } \\
\text { efisien. }\end{array}$ & $\begin{array}{c}\text { Customer } \\
\text { Perspective }\end{array}$ \\
\hline 3. & $\begin{array}{l}\text { Improve and } \begin{array}{r}\text { maintain } \\
\text { business } \\
\text { functionality. }\end{array} \\
\text { process }\end{array}$ & 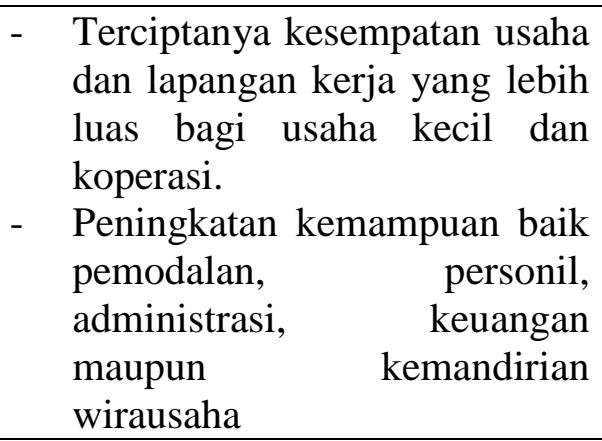 & \multirow[t]{4}{*}{$\begin{array}{c}\text { Internal } \\
\text { Perspective }\end{array}$} \\
\hline 4. & Lower process cost & $\begin{array}{l}\text { Peningkatan kemampuan baik } \\
\text { pemodalan, personil, administrasi, } \\
\text { keuangan maupun kemandirian } \\
\text { wirausaha. }\end{array}$ & \\
\hline 5. & $\begin{array}{l}\text { Provide compliance with } \\
\text { internal policies }\end{array}$ & $\begin{array}{l}\text { Pengendalian dan dukungan } \\
\text { pengambilan keputusan dalam hal } \\
\text { pelaporan yang aktual, akurat, } \\
\text { andal, multi dimensi, dan real- } \\
\text { time online monitoring system. }\end{array}$ & \\
\hline 6 & $\begin{array}{l}\text { Improve and maintain } \\
\text { operational and staff } \\
\text { productivity. }\end{array}$ & $\begin{array}{llr}\text { - } & \text { Terselenggaranya sistem } \\
\text { manajemen yang lebih rasional } \\
\text { dan efesien. } \\
\text { - } \\
\text { Membangun budaya } \\
\text { perusahaan yang sehat tercipta } \\
\text { saling menghargai dan } \\
\text { terbentuk integritas pribadi dan } \\
\text { profesionalisme. }\end{array}$ & \\
\hline 7 & $\begin{array}{l}\text { Acquire and maintain } \\
\text { skilled and motivated } \\
\text { people }\end{array}$ & $\begin{array}{l}\text { Membangun budaya perusahaan } \\
\text { yang sehat tercipta saling } \\
\text { menghargai dan terbentuk } \\
\text { integritas } \\
\text { profesionalisme }\end{array}$ & $\begin{array}{l}\text { Learning } \\
\text { and Growth } \\
\text { Perspective }\end{array}$ \\
\hline
\end{tabular}

COBIT 4.1 menetapkan business goal-nya dengan empat prespektif. Dari hasil pemetaan pada tabel 1 dapat diketahui bahawa perusahaan juga mencangkup keempat prespektif tersebut. Dari keempat prespektif tersebut dapat dilihat bahwa mayoritas berada pada prespektif internal. Hal ini menunjukan bahwa kondisi internal dari PT. Biro Klasifikasi Indonesia Cabang Makassar harus diperbaiki agar nantinya tujuan dari perusahaan sendiri dapat tercapai 


\subsection{Identifikasi IT Goals}

Setelah mengidentifikasi business goals langkah selanjutnya adalah mengindentifikasi IT Goals. COBIT sendiri sudah memetakan business goals dengan IT Goals, dan dari pemetaan itu dapat terlihat IT Golas apa saja yang nantinya akan menunjang business golas perusahaan. Berdasarkan business goals COBIT diatas kita dapat melihat IT Goals apa saja yang sesuai dengan PT.Biro Klasifikasi Indonesia Cabang Makassar seperti terlihat pada tabel 2 :

Tabel 2. Pemetaan Business Goals dengan IT Golas PT.Biro Klasifikasi Indonesia Cabang Makassar

\begin{tabular}{|c|c|c|c|c|c|c|c|}
\hline $\begin{array}{l}\text { Financial } \\
\text { Perspective }\end{array}$ & 1 & $\begin{array}{l}\text { Provide a good return on investment } \\
\text { of IT-enabled business investment. }\end{array}$ & 24 & & & & \\
\hline $\begin{array}{l}\text { Customer } \\
\text { Perspective }\end{array}$ & 4 & $\begin{array}{l}\text { Improve costumer orientation and } \\
\text { service }\end{array}$ & 3 & 23 & & & \\
\hline \multirow{4}{*}{$\begin{array}{l}\text { Internal } \\
\text { Perspective }\end{array}$} & 10 & $\begin{array}{l}\text { Improve and maintain business } \\
\text { process functionality. }\end{array}$ & 6 & 7 & 11 & & \\
\hline & 11 & Lower process cost & 7 & 8 & 13 & 15 & 24 \\
\hline & 13 & $\begin{array}{l}\text { Provide compliance with internal } \\
\text { policies }\end{array}$ & 2 & 13 & & & \\
\hline & 15 & $\begin{array}{l}\text { Improve and maintain operational } \\
\text { and staff productivity. }\end{array}$ & 7 & 8 & 11 & 13 & \\
\hline $\begin{array}{l}\text { Learning } \\
\text { and Growth } \\
\text { Perspective }\end{array}$ & 17 & $\begin{array}{l}\text { Acquire and maintain skilled and } \\
\text { motivated people }\end{array}$ & 9 & & & & \\
\hline
\end{tabular}

Berdasarkan hasil pemetaan table 2 dapat dilihat bahwa IT Goals COBIT yang sesuai dengan PT. Biro Klasifikasi
Indonesia Cabang Makassar adalah seperti terlihat pada tabel 3, berikut :

Tabel 3. IT Goals Yang Teridentifikasi Pada PT. Biro Klasifikasi Indonesia Cabang Makassar

\begin{tabular}{|c|c|}
\hline 2 & Respond to governance requirements in line with board direction. \\
\hline 3 & Ensure satisfaction end users with service offering and service levels. \\
\hline 6 & $\begin{array}{l}\text { Define how business functional and control requrements are translated in } \\
\text { effective and efficient automated solutions. }\end{array}$ \\
\hline 7 & Acquire and maintain integrated and standardized application system. \\
\hline 8 & Acquire and maintain an integrated and standardized IT infrastructureIT. \\
\hline 9 & Acquare and maintain IT skill that respond to the IT Strategy. \\
\hline 11 & Ensure seamless integration of application into business process. \\
\hline 13 & $\begin{array}{l}\text { Ensure proper use and perrformances of the applications and technology } \\
\text { solutions. }\end{array}$ \\
\hline
\end{tabular}

\section{KESIMPULAN DAN SARAN}

\subsection{Kesimpulan}

Setelah melakukan analisis dan pembahasan penelitian tesis perancangan tata kelola TI di PT. Biro Klasifikasi Indonesia Cabang Makassar, maka dapat ditarik beberpa kesimpulan antara lain : 
Hasil dari penelitian yang telah dilakukan terkait dengan tata kelola TI di PT. Biro Klasifikasi Indonesia Cabang Makassar saat ini, terdapat empat (4) domain proses dalam framework COBIT 4.1 yang berhasil diidentifikasi sebagai berikut :

1) Domain Plan and Organize sebanyak tiga (3) proses yaitu : proses PO1, PO7, dan PO10.

2) Domain Acquire and Implement sebanyak dua (2) proses yaitu : AI3 dan AI4.

3) Domain Delivery and Support sebanyak empat (4) proses yaitu : DS5, DS6, DS7, dan DS11.

4) Domain Monitoring and Evalute sebanyak satu (1) proses yaitu :

ME1.

\subsection{Saran}

Saran yang dapat diberikan pada penelitian ini adalah :

1) Penelitian lebih lanjut mengenai perancangan tata kelola TI di PT. Biro Klasifikasi Indonesia Cabang Makassar diharapkan dapat mendefenisikan ukuran-ukuran performasi yang lebih detail dari seluruh proses-proses TI terpilih yang telah diimplementasikan.

2) Manajemen PT. Biro Klasifikasi Indonesia Cabang Makassar agar lebih memperhatikan pengendalian internal perusahaan agar nantinya dapat tercipta tata kelola teknologi informasi yang lebih baik lagi

\section{DAFTAR PUSTAKA}

Ade putri Marina, Surendro Kridanto. Perencanaan Model Kapabilitas Proses Pengelolaan Sumber Daya Teknologi Informasi Pada PT.KAI ( Persero ) Menggunakan COBIT 4.1
Framework .Bandung. Institut Teknologi Bnadung.2012.

COBIT Steering Committee and the IT Governance Institute. Implementation Tool. USA: IT Governance Institute. 2009

The IT Governance Institute. (2007). COBIT 4.1: Framework for IT Governance and Control. In Governance An International Journal Of Policy And Administration. 